\title{
Focused Bedside Ultrasound Training Program for Surgical Residents in the Intensive Care Unit of Tertiary hospital
}

\author{
Kyoung Moo $\mathrm{Im}^{1}\left[\right.$ [ $\cdot$ Eun Young $\mathrm{Kim}^{2}$ (])
}

Received: 11 November 2021 / Accepted: 22 January 2022 /Published online: 8 February 2022

(c) The Author(s) 2022

\begin{abstract}
Bedside ultrasound has become one of the most important noninvasive and readily available diagnostic tools for critically ill patients. However, the current ultrasound training program for surgical residents is not standardized and is mostly unavailable to all surgical residents equally. Herein, we evaluated the effectiveness of the new training program in bedside ultrasound for surgical residents. Postgraduate residents (years 1 to 4 ) from the department of general surgery in a tertiary hospital attended the newly designed, 8-week ultrasound training course at the surgical intensive care unit. Didactic and experimental lectures about basic ultrasound physics and machine usage were delivered, followed by daily hands-on training to actual patients. Each participant documented their ultrasound findings and completed a self-assessment survey of ultrasound skills using the Likert scale. A total of 44 residents were enrolled, and only $36.4 \%$ of them were previously exposed to bedside ultrasound experience. Following the completion of the training course, the proficiency levels and the objective structured assessment of ultrasound skill scores showed significant improvement in every element $(P<0.001)$. The mean differences in pre- and post-course scores between post-graduate years and post hoc analysis revealed that the post-graduate year 2 group showed a higher improvement in most elements. Whether or not residents had previous experience with ultrasound, the significant improvement was seen in post-course scores. The knowledge and confidence of surgical residents in bedside ultrasound could be improved after our short training curriculum. Such education should be encouraged for all surgical residents to enhance their competency in performing bedside ultrasounds and use in managing critically ill patients.
\end{abstract}

Keywords Ultrasound $\cdot$ Training $\cdot$ Surgical resident $\cdot$ Education $\cdot$ Clinical competence

\begin{tabular}{ll}
\multicolumn{2}{l}{ Abbreviations } \\
OSAUS & $\begin{array}{l}\text { Objective structured assessment of ultrasound } \\
\text { skill }\end{array}$ \\
ICU & $\begin{array}{l}\text { Intensive care unit } \\
\text { PGY }\end{array}$ \\
Postgraduate year \\
e-FAST & $\begin{array}{l}\text { Extended-focused assessment with sonography } \\
\text { for trauma }\end{array}$ \\
IVC & Inferior vena cava
\end{tabular}

Eun Young Kim

freesshs@naver.com

1 Department of Surgery, Seoul St. Mary's Hospital, Seoul, Korea

2 Division of Trauma and Surgical Critical Care, Department of Surgery, Seoul St. Mary's Hospital, College of Medicine, The Catholic University of Korea, Seoul, Korea

\section{Introduction}

To surgeons, the use of ultrasound has proven to be a valuable tool in enhancing the level of care to patients. It provides physicians various help in different settings such as in the emergency department, operating room, or intensive care unit (ICU) [1,2]. As a quick and noninvasive diagnostic tool, it could be used for detecting free fluid in trauma patients, facilitating rapid diagnosis of shock etiology, or determining the fluid status of critically ill patients [1-3]. Moreover, the use of ultrasound-guided procedures is becoming the gold standard in many clinical settings, such as central venous catheter placement, drainage insertion, or aspiration of fluid collection $[4,5]$. Especially in the ICU, where most of the patients are immobilized and hemodynamically unstable, bedside ultrasonography is very useful. Patients do not have to leave the ICU for studies or procedures, can be performed in a serial fashion, and allows rapid assessment of critically ill patients [6-9]. 
Due to the advantages of ultrasound in various clinical settings with the recognition that ultrasound is operator dependents, the American College of Surgeons has been providing ultrasound courses in the US since 1996 [4]. In South Korea, the Korean Surgical Society mandates that all residents in general surgery attain competency in the use of ultrasound for various surgeries. However, a previous study showed only $27.7 \%$ of medical schools in the United States have a formal ultrasound education [10]. Additionally, many surgical residents still lack practical opportunities or adequate training curriculum, possibly due to curricular time constraints, lack of equipment, and limited availability of skilled faculty $[9,11]$. Despite the obvious advantages of sonography, this had led to minimal opportunities of ultrasound training or inexperience in ultrasound for most of the surgical residencies during their training period. Therefore, the implementation of a formal and well-established training program in bedside ultrasonography is important for surgical residents $[12,13]$.

Herein, we introduced our 8-week standardized multimodal ultrasound training program that includes clinical application of skills to the actual ICU patients. The hypothesis was that this short and newly developed curriculum would help increase the confidence level of residents after training.

\section{Methods}

\section{Participants and Methods}

From March 2019 to February 2021, all residents of the department of general surgery in our institution from postgraduate year-1 (PGY-1) to 4 (PGY-4) enrolled in the study. The training program consisted of didactic lectures and hands-on sessions of bedside ultrasound, including extended-focused assessment with sonography for trauma (e-FAST) examination and a volume assessment of the patients admitted to the surgical ICU. After each training session, the residents evaluated their own competency in performing ultrasound examinations (Appendices Figures 3 and 4 ) and documented the findings of each patient (Appendix Figure 5). None of the data collected were linked to individual participants, so the results of the assessment did not have any impact on assessing the individual participants' abilities. The ultrasound machine used for the program was GE Healthcare LOGIQ P9 (Boston, MA). A convex transducer (C1-5, low frequency, 2-5 MHz) and a linear transducer (3SC, high frequency, 1.7-4 MHz) were used for training and assessment.

\section{Ultrasound Training}

A multimodal training approach was used, including didactic lectures and hands-on ultrasound examinations of ICU patients under the supervision of an instructor. The didactic lectures were developed by the surgeons who specialized in trauma and surgical critical care. Each resident received 1-h didactic lecture once a week. The lecture included basic physics of ultrasound, knobology, artifacts, e-FAST technique, and a technique for assessing inferior vena cava (IVC) diameter. The same surgeon also conducted and supervised the hands-on sessions. Residents performed a bedside ultrasound examination including e-FAST and assessed the diameter of the IVC. Moreover, each resident focused on visualization of organs (lung, liver, spleen, bladder, kidney, and heart) and tried to identify any abnormal findings, as shown in Fig. $1[2,6-8]$.

To assess the diameter of IVC, either curvilinear or phased array probes were used on the subcostal window and scanned transverse images of IVC and right atrium (Fig. 2). A probe was rotated $90^{\circ}$ to obtain the long axis of IVC. The longest and the shortest diameters of IVC were measured at $2 \mathrm{~cm}$ away from the right atrium junction. The M-mode scan was used to capture both the longest and the shortest diameters of IVC on a single image. IVC collapsibility index was calculated using the following formula. After each hands-on session, attending physicians give feedback and review the residents' documentation of ultrasound findings.

IVC collapsibility index formulae:

IVC collapsibility index $=\frac{\text { IVC longest diameter }- \text { IVC shortest diameter }}{\text { IVC longest diameter }} \times 100(\%)$

\section{Study Endpoint and Outcome Measurement}

The primary outcomes included assessment of basic knowledge and ultrasound competency of each resident as well as the efficacy of an ultrasound training program based on the comparative evaluation of the perceived self-confidence levels before and after the training measured on a 5-point Likert scale. The secondary outcome measures were to assess differences in the program efficacy by postgraduate year or previous experience in bedside ultrasonography. 
Chest

Pleural effusion

Pneumothorax

Pulmonary edema

Pneumonia

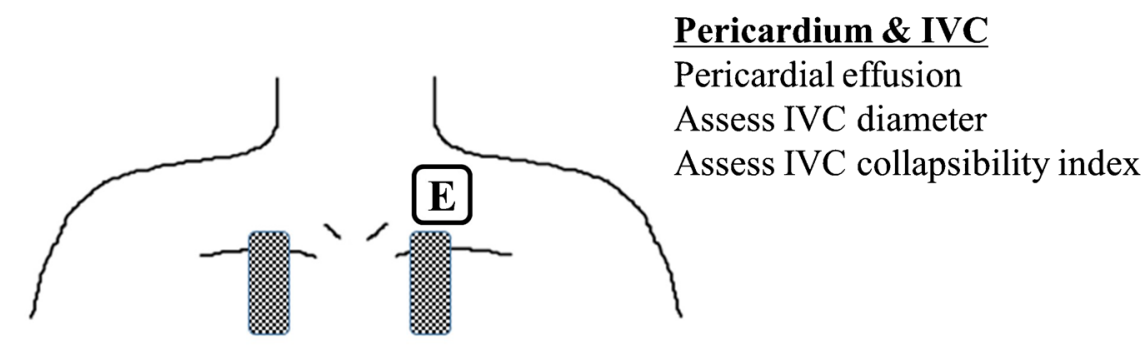

Pericardium \& IVC

Pericardial effusion

Assess IVC diameter

Assess IVC collapsibility index $\underline{\text { Liver }}$

Fluid collection at Morrison's pouch

Liver laceration

Liver abscess

Liver infarction

Cholecystitis

Cholelithiasis

Kidney

Kidney laceration

Hydronephrosis
0

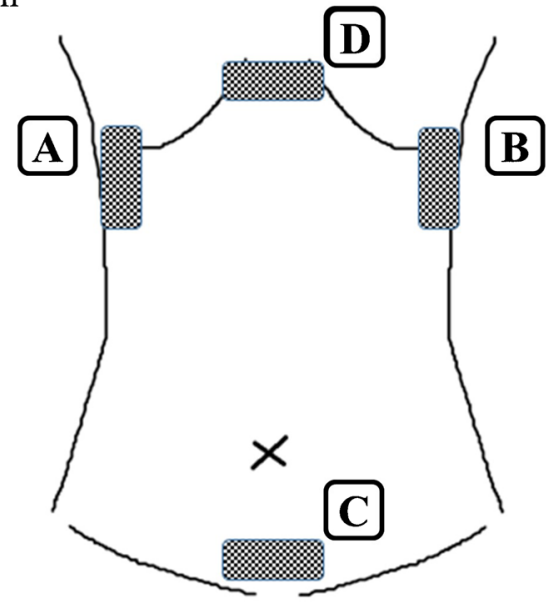

$\underline{\text { Spleen }}$

Fluid collection at splenorenal angle Spleen laceration

Spleen abscess

Spleen infarction

\section{Pelvis}

Fluid collection at pouch of Douglas

Pneumothorax

Pulmonary edema

Pneumonia

Fig. 1 The four abdominal views and chest view. A Morrison's pouch and the right diaphragm, B spleno-renal angle and left diaphragm, C pelvis in both longitudinal and transverse planes, $\mathbf{D}$ pericardial, and $\mathbf{E}$ pleura (bilaterally)

\section{Participants' Self-assessment}

Participating residents completed the surveys to assess their own comprehension (Appendix Figure 3) and to evaluate the objective structured assessment of ultrasound skill (OSAUS) (Appendix Figure 4). All questionnaires were estimated using a 5 -point Likert scale $(1=$ not confident at all, and $5=$ very confident). The Likert scale is an orderly scale and a form of a closed question that is most widely used in the analysis of opinions or educational training. Its advantage relates to the absence of forced expression to elicit participants' opinions [5, 14-19]. We investigated how the residents perceived their own confidence and proficiency during the overall examination and queried in detail according to different areas (lung, pleural effusion, bowel, peritoneal cavity, liver, gallbladder, spleen, jugular vein, and inferior vena cava). Furthermore, the resident's competency was also assessed using Delphi's OSAUS, which is a generic ultrasound rating scale based on international multispecialty consensus [20]. We modified the original form of OSAUS by including queries based on five elements: applied knowledge of ultrasound equipment, image optimization, systematic examination, image interpretation, and documentation of examination.

\section{Statistical Analysis}

All statistical analyses were conducted using SPSS statistical package software (version 21.0 for Windows; SPSS, Inc., Chicago, IL). Survey responses to questions regarding confidence ranged from 1 (not confident at all) to 5 (very confident). For the purpose of statistical analysis, responses were divided into "not confident (not confident, minimally confident, and neutral, based on scores ranging from 1 to 3 ) and "confident" (confident and very confident, based on scores from 4 to 5). To assess the differences in confidence levels, we compared the demographics, previous training history, as well as other variables of residents who reported confidence with training compared with those who did not. Continuous data are presented as the mean \pm standard deviation. For continuous data, overall differences were tested by Student's 

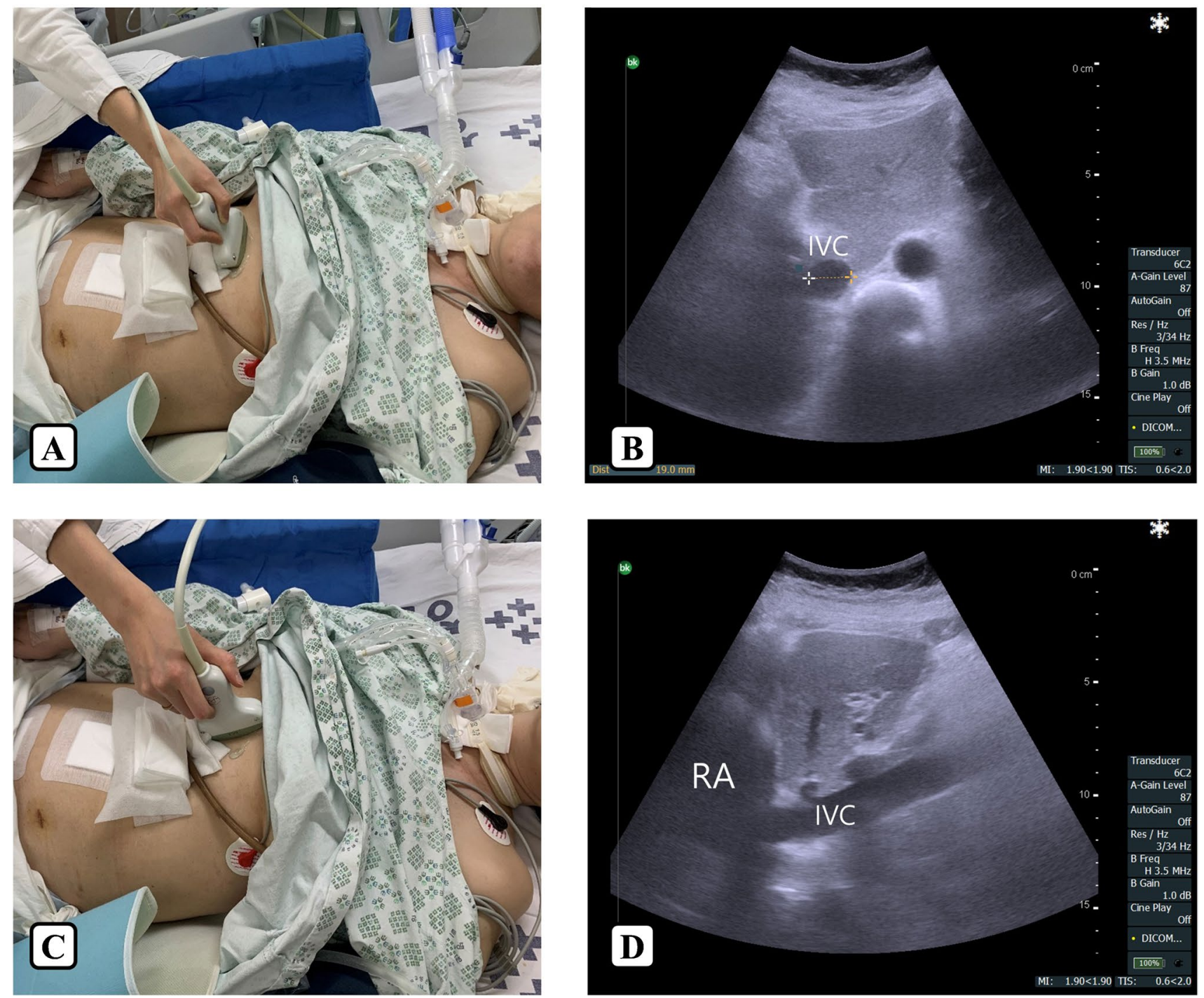

Fig. 2 Participant evaluating the IVC diameter and its respiratory variation. A, B First IVC should be identified in a transverse plane, in a subxiphoid position perpendicular to the skin. C, D The probe

is rotated by $90^{\circ}$ to obtain a longitudinal plane. Identify the entrance of the IVC into the right atrium. Then the IVC diameter can be measured at one to two centimeters away from the right atrium

$t$-test or ANOVA. The categorical variables were calculated using Fisher's exact test or chi-square test. The descriptive statistics are described as means \pm standard deviation, and differences were regarded as statistically significant when $P<0.05$. Multivariable logistic regression analysis was then performed to identify independent predictive factors.

\section{Results}

During the study period, 44 residents from PGY-1 to PGY-4 completed our 8 weeks of bedside ultrasound training program at the surgical ICU. Among them, only sixteen participants $(36.3 \%)$ were experienced in bedside ultrasound

before the training. The definition of an experienced group is the participants who had formal ultrasound education and performed bedside ultrasound at least five times in a clinical setting prior to study enrollment. The average number of experiences of the experimental group before the study enrollment was 5.8, whereas the average number of the nonexperienced group was 0.9 . A total of 4872 ultrasound examinations with 818 patients were completed and analyzed. The mean age of patients was $67.2 \pm 16.3$, and the majority of them were from the departments of lower gastrointestinal surgery $(n=221,27 \%)$ followed by hepatobiliary-pancreas surgery $(n=180,22 \%)$. The patient demographics and sonographic findings are summarized in Table 1. 
Table 1 Demographic characteristics of enrolled cases

\begin{tabular}{|c|c|c|}
\hline \multicolumn{2}{|l|}{ Variables } & \multirow{2}{*}{$N(\%)$ or mean $\pm \mathrm{SD}$} \\
\hline \multicolumn{2}{|l|}{ Trainee $(N=44)$} & \\
\hline \multirow[t]{4}{*}{ Postgraduate year } & 1 & 11 \\
\hline & 2 & 9 \\
\hline & 3 & 9 \\
\hline & 4 & 15 \\
\hline Previous experience of bedside sonogram* & Experienced/inexperienced & $16 / 28$ \\
\hline \multirow{2}{*}{$\begin{array}{l}\text { Number of experiences of bedside sonogram } \\
\text { before the study enrollment }\end{array}$} & Experienced group & $5.8 \pm 4.3$ \\
\hline & Inexperienced group & $0.9 \pm 4.3$ \\
\hline \multicolumn{3}{|l|}{ Patient demographics $(N=818)$} \\
\hline Age & & $67.2 \pm 16.3$ \\
\hline Sex & Male/female & $530 / 288$ \\
\hline ICU HD at the time of sonogram & & $6.8 \pm 7.8$ \\
\hline POD at the time of sonogram & & $4.2 \pm 6.1$ \\
\hline \multirow[t]{6}{*}{ Clinical department } & Upper GI & $139(17)$ \\
\hline & Lower GI & $221(27)$ \\
\hline & Hepatobiliary-pancreas & $180(22)$ \\
\hline & Vascular & $149(18.2)$ \\
\hline & Trauma & $87(10.6)$ \\
\hline & Miscellaneous & $42(5.1)$ \\
\hline \multicolumn{3}{|l|}{ Sonographic findings $(N=4872)$} \\
\hline \multirow[t]{3}{*}{ Chest } & Pleural effusion & $1203(24.7)$ \\
\hline & Pneumothorax & $10(0.2)$ \\
\hline & Pulmonary edema & $465(9.5)$ \\
\hline \multirow[t]{3}{*}{ Hepatobiliary (liver, GB, pancreas, spleen) } & Fluid collection & $429(8.8)$ \\
\hline & Mass or hematoma & $97(2)$ \\
\hline & Cholecystitis or stone, polyp & $395(8.1)$ \\
\hline \multirow[t]{3}{*}{ Abdomen and pelvis } & Fluid collection & $925(19)$ \\
\hline & Mass or hematoma & $243(5)$ \\
\hline & Hydronephrosis & $49(1)$ \\
\hline \multirow[t]{4}{*}{ IVC dilatation } & Normal & $1765(36.2)$ \\
\hline & Collapsed & $1429(29.3)$ \\
\hline & Dilated & $1352(27.8)$ \\
\hline & Not checkable & $331(6.8)$ \\
\hline IVC collapsibility index ${ }^{* *}$ & & $19.6 \pm 13.8$ \\
\hline
\end{tabular}

*An experienced group is defined as the participants who had performed bedside ultrasound at least five times in a clinical setting prior to study enrollment. A participant in which the average number of experiences of bedside ultrasound before the study enrollment was less than five was defined as the inexperienced group. ${ }^{* * *}$ The IVC collapsibility index $($ IVCCI $=[(I V C e-$ IVCi $) /$ IVCe $] \times 100 \%)$ was calculated as the IVC provided respiratory variation. The inspiratory (IVCi) and respiratory (IVCe) diameters of the IVC were detected by measuring the vein lumen at 1 respiratory cycle
Based on the proficiency and OSAUS scores, there was a significant increase in the participants' confidence level measured after the training course across all areas $(P<0.001)$ compared with the level measured before the training. In subgroup analysis, junior residents (PGY-1 and PGY-2) showed less improvement in the post-course score, whereas PGY-4 showed significant improvement in every element measured $(P<0.001)$, as shown in Table 2. Additionally, the maximum improvement in all elements was observed in the proficiency score of lung parenchyma (pre-course score $=2.1 \pm 0.7$, post-course score $=4 \pm 1$ ). Table 3 presents the comparative analysis of mean differences before and after the training course of each PGY group. The degree of improvement between the PGY groups showed significant differences in the proficiency of manipulation and OSAUS scores after the training, except for the proficiency in the peritoneal cavity. The post hoc test was performed to compare the results 


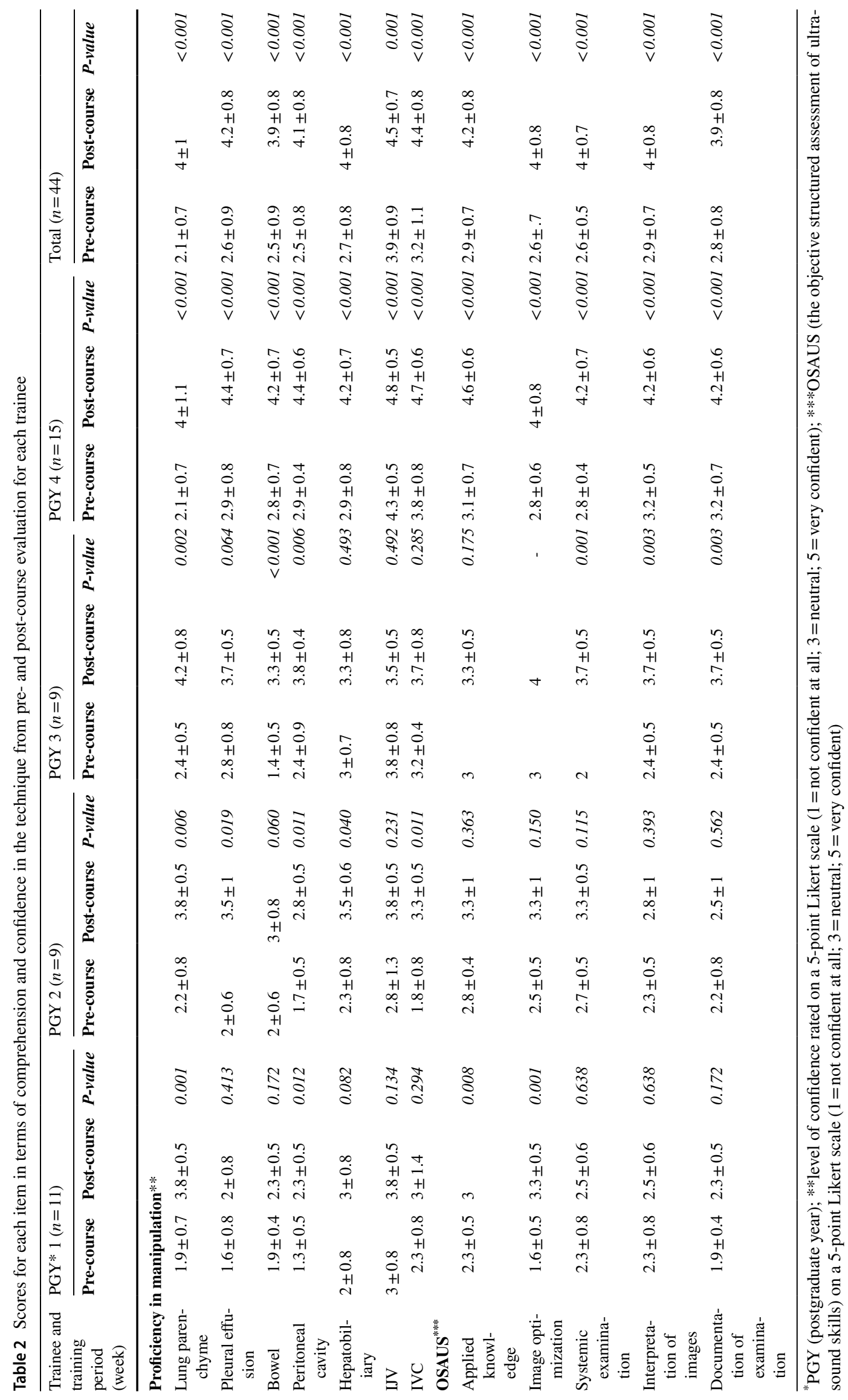




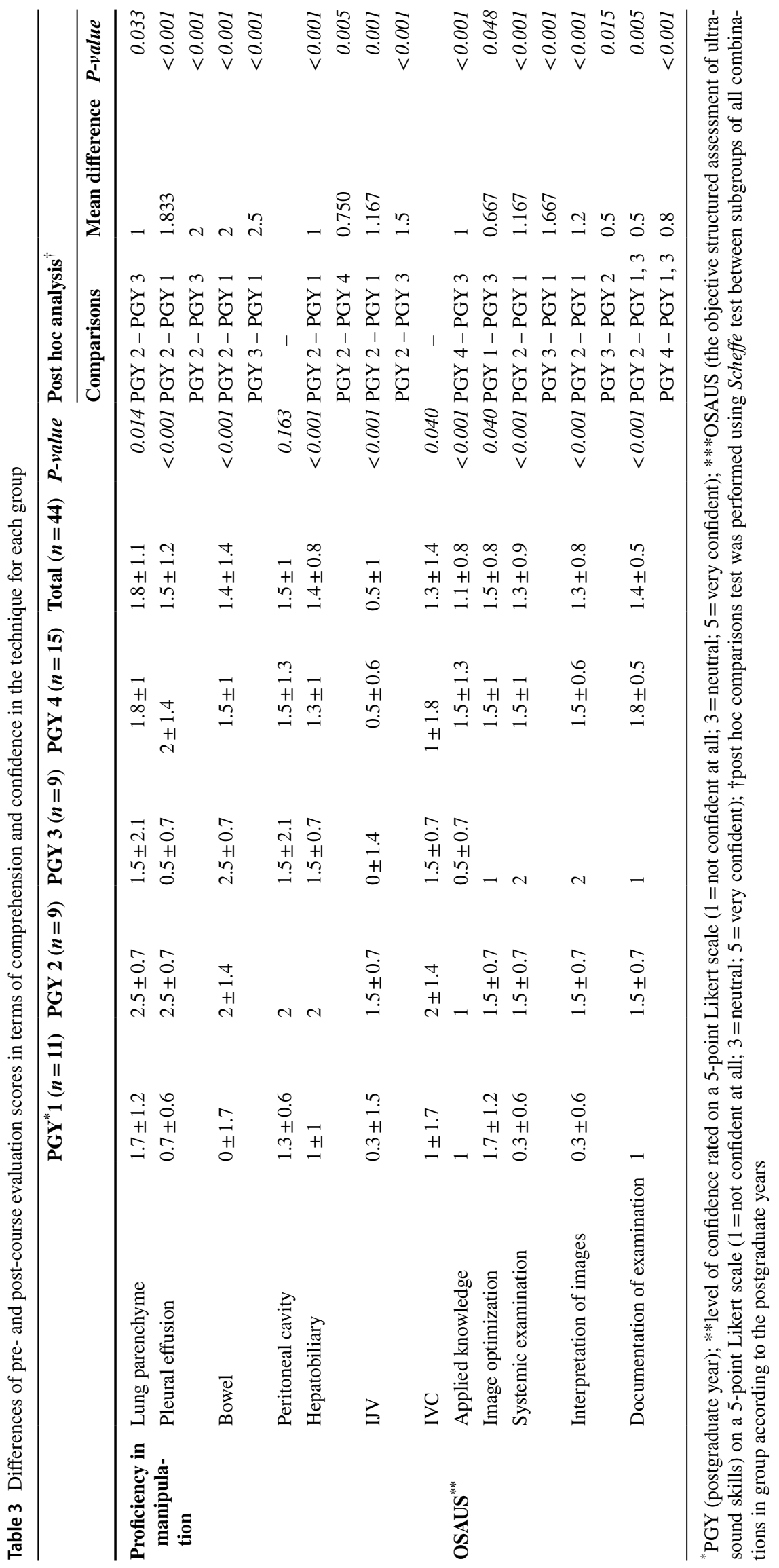


Table 4 Differences of pre- and post-course evaluation in terms of comprehension and confidence in the technique* of experienced and inexperienced residents (average of mean difference)

\begin{tabular}{|c|c|c|c|c|c|c|c|}
\hline & \multicolumn{3}{|c|}{ Experienced $(n=16)$} & \multicolumn{3}{|c|}{ Inexperienced $(n=28)$} & \multirow[t]{2}{*}{$P$-value } \\
\hline & Pre-course & Post-course & P-value & Pre-course & Post-course & P-value & \\
\hline \multicolumn{8}{|l|}{ Proficiency in manipulation } \\
\hline Lung parenchyme & $2.1 \pm 0.7$ & $4 \pm 1.1$ & $<0.001$ & $2.1 \pm 0.7$ & $4 \pm 0.7$ & $<0.001$ & 0.594 \\
\hline Pleural effusion & $2.9 \pm 0.8$ & $4.4 \pm 0.7$ & $<0.001$ & $2.1 \pm 0.9$ & $3.6 \pm 0.7$ & $<0.001$ & $<0.001$ \\
\hline Bowel & $2.8 \pm 0.7$ & $4.2 \pm 0.7$ & $<0.001$ & $1.8 \pm 0.9$ & $3.2 \pm 0.6$ & $<0.001$ & 0.390 \\
\hline Peritoneal cavity & $2.9 \pm 0.4$ & $4.4 \pm 0.6$ & $<0.001$ & $1.7 \pm 0.8$ & $3.4 \pm 0.7$ & $<0.001$ & 0.748 \\
\hline Hepatobiliary & $2.9 \pm 0.8$ & $4.2 \pm 0.7$ & $<0.001$ & $2.4 \pm 0.9$ & $3.4 \pm 0.7$ & 0.004 & 0.272 \\
\hline IJV & $4.3 \pm 0.5$ & $4.8 \pm 0.5$ & $<0.001$ & $3.2 \pm 1$ & $3.6 \pm 0.5$ & 0.231 & 0.679 \\
\hline IVC & $3.8 \pm 0.8$ & $4.7 \pm 0.6$ & $<0.001$ & $2.4 \pm 0.9$ & $3.5 \pm 0.7$ & 0.002 & 0.167 \\
\hline \multicolumn{8}{|l|}{ OSAUS $^{* *}$} \\
\hline Applied knowledge & $3.1 \pm 0.7$ & $4.6 \pm 0.6$ & $<0.001$ & $2.7 \pm 0.5$ & $3.3 \pm 0.7$ & 0.008 & 0.002 \\
\hline Image optimization & $2.8 \pm 0.6$ & $4 \pm 0.8$ & $<0.001$ & $2.3 \pm 0.8$ & $3.7 \pm 0.7$ & $<0.001$ & 0.666 \\
\hline Systemic examination & $2.8 \pm 0.4$ & $4.2 \pm 0.7$ & $<0.001$ & $2.3 \pm 0.6$ & $3.5 \pm 0.5$ & $<0.001$ & 0.048 \\
\hline Interpretation of images & $3.2 \pm 0.5$ & $4.2 \pm 0.6$ & $<0.001$ & $2.3 \pm 0.6$ & $3.3 \pm 0.8$ & 0.001 & 0.010 \\
\hline Documentation of examination & $3.2 \pm 0.7$ & $4.2 \pm 0.6$ & $<0.001$ & $2.1 \pm 0.6$ & $3.2 \pm 0.9$ & 0.001 & $<0.001$ \\
\hline
\end{tabular}

*Level of confidence rated on a 5 -point Likert scale $(1=$ not confident at all; $3=$ neutral; $5=$ very confident); **OSAUS (the objective structured assessment of ultrasound skills) on a 5 -point Likert scale ( $1=$ not confident at all; $3=$ neutral; $5=$ very confident $)$

between the groups classified according to the residency year. In the comparison based on residency year, PGY-2 showed the most significant improvement. PGY-2 showed significant differences in five of seven elements involving proficiency in manipulation and three of five elements in the OSAUS score, whereas PGY-1 showed differences in a single element. The largest mean differences were seen in the proficiency score of bowel between PGY-3 and PGY-1, (mean difference $=2.5, P<0.001$ ) followed by PGY-2 and PGY-1 (mean difference $=2, P<0.001$ ). The post hoc test showed no differences in the proficiency scores of peritoneal cavity and IVC between any of the PGY groups.

As shown in Table 4, we also performed a subgroup analysis and compared experienced and inexperienced residents to determine if previous exposure to training and bedside sonograms affected the results. Both groups demonstrated significantly higher confidence after the completion of the course in all areas of evaluation. Comparing the advances between the two groups, only proficiency in manipulation score involving pleural effusion showed differences in the degree of improvement (experienced 2.9 versus 4.4 , inexperienced 2.1 versus 3.6. $P<0.001)$ in the OSAUS score, experienced residents showed better improvement except in image optimization $(P=0.666)$. Experienced residents achieved significantly higher post-course confidence levels than inexperienced residents.

\section{Discussion}

Based on our results, surgical residents showed a significant improvement in ultrasound basics and focused assessment of bedside sonography for critically ill patients after completion of our training curriculum. Additionally, the senior residents (PGY-3 and 4) showed a significant increase in scores in a wide range of areas than junior residents. Moreover, regardless of prior experience with performing bedside sonography, all residents showed significant improvement after the training course.

Ultrasound is widely used in diagnostic and procedural guidance and in routine clinical practice owing to its efficacy and safety [2]. Technological advances have led to a high-performance ultrasound, which is increasingly compact and portable. Thus, ultrasonography can enable the acquisition of real-time images by the clinician at the bedside. Proper training and use of ultrasound facilitate surgical diagnosis and improve the success rate of invasive procedures [6]. Especially in trauma or critically ill patients, the usage of bedside ultrasound can enable the identification of the etiology of certain conditions such as hypotensive shock or respiratory failure. The e-FAST examination has a sensitivity of 73-99\%, a specificity of 94-98\%, an overall accuracy of $90-98 \%$ for intra-abdominal injury in trauma, and a sensitivity of $78.6 \%$ and a specificity of $98.4 \%$ for 
detecting pneumothorax $[6,21]$. The need for additional diagnostic tests such as CT scans can be reduced, thus shortening the time that takes to implement appropriate intervention [7]. The previous study even showed inexperienced learners could perform bedside sonographic examination easily, with proficiency and accuracy comparable to that of a radiologist [22, 23]. However, despite these advantages, a formal training curriculum in ultrasound is still lacking in many surgical residencies. Our results showed that most residents were unfamiliar with the use of ultrasound or performing bedside ultrasound. However, after the completion of the ultrasound training program, they could achieve a significant improvement in their knowledge and confidence. We expect that a well-organized and systematic ultrasound training could ultimately enhance the residents' ability to manage patients since the residents conduct initial resuscitation and the primary management.

Our results are shown in Table 2 suggest that the precourse scores in proficiency and OSAUS were similarly low regardless of PGY. After the training course, PGY-4 showed improvement in every area of evaluation, while only a few areas showed improvement in PGY-1. It is probably because senior residents have more experience in clinical settings involving relatively diverse surgery. Prior knowledge of the key elements of the altered anatomy after the surgery or specific findings related to the clinical condition can facilitate the evaluation of the subjects more intensively during the ultrasound examination. It will enable the educational and learning outcomes during the training. Therefore, we expect that the trainees with prior knowledge and understanding of patients' anatomy can be benefited more from our training program.

Noteworthy, PGY-2 exhibited the most significant improvement after training evaluation in our results. In Table 3, when comparing responses of our program by training years, significant differences existed between PGY groups. Except in applied knowledge and image optimization, PGY-2 showed a higher mean difference in most elements than the other groups. However, PGY-4 had the highest post-course scores, and the pre-course score was higher than in PGY-2, which explains why our senior residents did not show a higher mean difference than PGY-2. PGY-1 exhibited the lowest responses after the training program, which could be attributed to a limited understanding of anatomical structure and experience of clinical settings. Therefore, we expect that our training program would be most suitable and most effective for surgical residents with at least basic knowledge of surgical anatomy and clinical experience, such as in the case of PGY-2.
When comparing the scores according to previous ultrasound experience before training, residents with prior experiences showed higher pre-course scores than those without experiences. After completing the training course, there was a meaningful improvement in scores in both groups. These results suggest that our ultrasound training program can help trainees with less experience in ultrasound manipulations acquire ultrasound skills and clinical interpretation more effectively by providing dense hands-on opportunities for short periods of time. Our training program is not only useful to novice residents but also enhances the understanding and confidence levels of non-beginners with little experience.

Despite these interesting findings, the current study had few limitations. Firstly, this study had a small number of trainees and involved only one institution. Consequently, our training results may not be generalized to other institutions. To establish the reliability and reproducibility of our results, a large-scale study with a large number of trainees across different training hospitals is needed. Secondly, this study did not assess the accuracy of the resident's ability to perform and interpret the ultrasound. We only assessed their confidence in the use of ultrasound. In order to use ultrasound in medical practice, the efficacy and accuracy of performance should be evaluated in the further study [24, 25]. Thirdly, unlike other ultrasound training programs, we did not use a simulator or healthy human model. In our program, we performed ultrasound in actual patients who underwent surgeries or patients who were in an unstable condition. Therefore, it was not easy to identify every structure or visualize a normal image of an uninjured organ.

Despite these shortcomings, our results give awareness of the absence of surgical residents' ultrasound education. There is a need for an appropriate ultrasound training program to enhance the resident's ultrasound skills and confidence effectively. We believe that a prospective multi-center trial with a large number of participants should be conducted in the near future to corroborate our study results.

\section{Conclusion}

Our short and intensive bedside ultrasound training program improves the confidence of all surgical residents regardless of their postgraduate years or prior experiences. Given the diversity of applications of bedside ultrasound in surgical medicine, we believe that our training curriculum in bedside ultrasound for critical patients would be beneficial for all surgical residencies. 


\section{Appendix}

Figures 3, 4 and 5

Fig. 3 Survey used to evaluate residents' comprehension and confidence of ultrasound skills

\begin{tabular}{|c|c|c|c|c|c|}
\hline \multicolumn{6}{|l|}{ I. survey question } \\
\hline \multirow{2}{*}{ Survey question } & \multicolumn{5}{|c|}{ Answer by scoring to question } \\
\hline & 1 & 2 & 3 & 4 & 5 \\
\hline \multicolumn{6}{|l|}{$\begin{array}{l}\text { Rate your current competency in your } \\
\text { knowledge and skills in ultrasound. }\end{array}$} \\
\hline Rate your current competency in each organ. & 1 & 2 & 3 & 4 & 5 \\
\hline \multicolumn{6}{|l|}{ Lung } \\
\hline \multicolumn{6}{|l|}{ Pleural effusion } \\
\hline \multicolumn{6}{|l|}{ Bowel } \\
\hline \multicolumn{6}{|l|}{ Peritoneal cavity / Ascites } \\
\hline \multicolumn{6}{|l|}{ Liver / GB / spleen } \\
\hline \multicolumn{6}{|l|}{ Internal jugular vein } \\
\hline IVC & & & & & \\
\hline
\end{tabular}


Fig. 4 Survey used to evaluate trainees' objective structured assessment of ultrasound skills

\section{The Objective Structured Assessment of Ultrasound Skills (OSAUS)}

\begin{tabular}{|c|c|c|c|c|c|}
\hline $\begin{array}{l}\text { 1. Applied knowledge of ultrasound } \\
\text { equipment } \\
\text { - Feel comfortable with choosing the correct } \\
\text { probe for the exam, can choose correct } \\
\text { orientation of the probe and operating the } \\
\text { ultrasound. }\end{array}$ & $\begin{array}{l}1 \square \\
\text { unable to } \\
\text { operate } \\
\text { equipment }\end{array}$ & $2 \square$ & \begin{tabular}{|c|} 
\\
operates the \\
equipment with \\
some experience
\end{tabular} & $4 \square$ & $\begin{array}{c}5 \square \\
\text { familiar with } \\
\text { operating the } \\
\text { equipment }\end{array}$ \\
\hline $\begin{array}{l}\text { 2. Image optimization } \\
\text { - Feel comfortable adjusting the gain, depth } \\
\text { focus and frequency to maximize picture } \\
\text { quality. }\end{array}$ & $\begin{array}{l}1 \square \\
\text { fails to } \\
\text { optimize } \\
\text { images }\end{array}$ & $2 \square$ & \begin{tabular}{|c|}
$3 \square$ \\
competent image \\
optimization but \\
not done \\
consistently
\end{tabular} & $4 \square$ & $\begin{array}{l}5 \square \\
\text { consistent } \\
\text { optimization } \\
\text { of images }\end{array}$ \\
\hline $\begin{array}{l}\text { 3. Systemic examination } \\
\text { - Approach and visualize every view } \\
\text { (subcostal, right upper quadrant, left upper } \\
\text { quadrant, pelvis, chest, IVC) systematically } \\
\text { and present relevant structures according to } \\
\text { guidelines. }\end{array}$ & $\begin{array}{c}1 \square \\
\begin{array}{c}\text { unsystematic } \\
\text { approach }\end{array}\end{array}$ & $2 \square$ & $\begin{array}{c}\square \\
\text { displays some } \\
\text { systemic } \\
\text { approach }\end{array}$ & $4 \square$ & $\begin{array}{c}5 \square \\
\text { consistently } \\
\text { displays } \\
\text { systemic } \\
\text { approach }\end{array}$ \\
\hline $\begin{array}{l}\text { 4. Interpretation of images } \\
\text { - Feel confidence in interpreting the findings } \\
\text { and recognizing image pattern. }\end{array}$ & $\begin{array}{l}1 \square \\
\text { unable to } \\
\text { interpret any } \\
\text { findings }\end{array}$ & $2 \square$ & \begin{tabular}{|c|}
$3 \square$ \\
does not \\
consistently \\
interpret \\
findings correctly
\end{tabular} & $4 \square$ & $\begin{array}{c}5 \square \\
\text { consistently } \\
\text { interprets } \\
\text { findings } \\
\text { correctly }\end{array}$ \\
\hline $\begin{array}{l}\text { 5. Documentation of examination } \\
\text { - Describe examination findings, using } \\
\text { appropriate anatomic and terminology. }\end{array}$ & $\begin{array}{c}1 \square \\
\text { does not } \\
\text { document any } \\
\text { images }\end{array}$ & $2 \square$ & $\begin{array}{c}3 \square \\
\text { documents } \\
\text { most relevant } \\
\text { images }\end{array}$ & $4 \square$ & $\begin{array}{c}5 \square \\
\text { consistently } \\
\text { documents } \\
\text { relevant images }\end{array}$ \\
\hline
\end{tabular}


Fig. 5 Checklist for the bedside ultrasound examination including e-FAST and IVC volume assessment

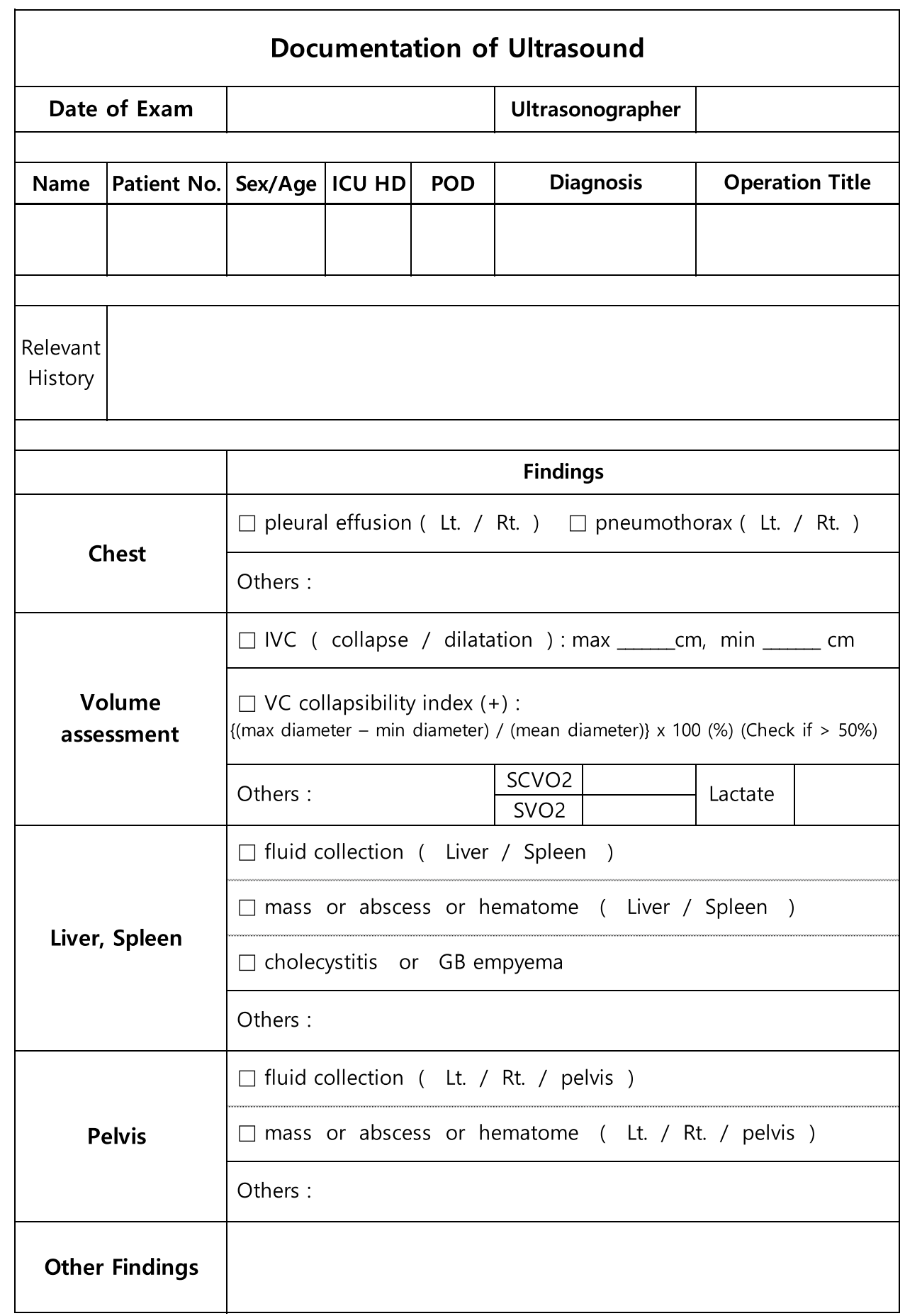


Acknowledgements The authors deeply appreciate the surgical residents and supervisors at Seoul St. Mary's Hospital who participated in the training course. The authors received no financial support for the research, authorship, and/or publication of this article.

Author Contribution KMI and EYK designed and conducted the study. KMI and EYK collected and analyzed the data. KMI drafted the manuscript, and EYK made a critical revision of the manuscript. All authors reviewed and approved the final version of the manuscript and agreed to be accountable for all aspects of the work in ensuring the questions related to the accuracy or integrity of any part of the work are appropriately investigated and resolved.

Funding This research did not receive any specific grant from funding agencies in the public, commercial, or not-for-profit sectors.

Availability of Data and Materials The dataset supporting the conclusions of this article is included within the article (and its additional file(s)) and can be obtained from the corresponding author on a reasonable request.

\section{Declarations}

Competing interest The authors declare no competing interests.

Open Access This article is licensed under a Creative Commons Attribution 4.0 International License, which permits use, sharing, adaptation, distribution and reproduction in any medium or format, as long as you give appropriate credit to the original author(s) and the source, provide a link to the Creative Commons licence, and indicate if changes were made. The images or other third party material in this article are included in the article's Creative Commons licence, unless indicated otherwise in a credit line to the material. If material is not included in the article's Creative Commons licence and your intended use is not permitted by statutory regulation or exceeds the permitted use, you will need to obtain permission directly from the copyright holder. To view a copy of this licence, visit http://creativecommons.org/licenses/by/4.0/.

\section{References}

1. Lee JH, Kang B, Kwon $\mathrm{H}$ et al (2014) The experience of emergency pediatric ultrasound education course. Pediatr Emerg Med J 1:34-41

2. Beggs AD, Thomas PR (2013) Point of use ultrasound by general surgeons: review of the literature and suggestions for future practice. Int J Surg 11:12-17

3. Ghane MR, Gharib M, Ebrahimi A et al (2015) Accuracy of early rapid ultrasound in shock (RUSH) examination performed by emergency physician for diagnosis of shock etiology in critically ill patients. J Emerg Trauma Shock 8:5

4. Nassour I, Spalding MC, Hynan LS, Gardner AK, Williams BH (2017) The surgeon-performed ultrasound: a curriculum to improve residents' basic ultrasound knowledge. J Surg Res 213:51-59

5. Carver TW (2018) Ultrasound training in surgical critical care fellowship: a survey of program directors. J Surg Educ 75:1250-1255

6. Moore CL, Copel JA (2011) Point-of-care ultrasonography. N Engl J Med 364:749-757

7. Cevik AA, Noureldin A, El Zubeir M, Abu-Zidan FM (2018) Assessment of EFAST training for final year medical students in emergency medicine clerkship. Turk J Emerg Med 18:100-104
8. Helling TS, Wilson J, Augustosky K (2007) The utility of focused abdominal ultrasound in blunt abdominal trauma: a reappraisal. Am J Surg. 194:728-732 (discussion 732-723)

9. Tripu R, Lauerman MH, Haase D et al (2018) Graduating surgical residents lack competence in critical care ultrasound. J Surg Educ 75:582-588

10. Dinh VA, Fu JY, Lu S, Chiem A, Fox JC, Blaivas M (2016) Integration of ultrasound in medical education at United States medical schools: a national survey of directors' experiences. J Ultrasound Med 35:413-419

11. Kim JS, Cho YS, Kim YS et al (2010) Development of an emergency abdominal ultrasound course in Korea: 1-year experience. J Korean Soc Emerg Med. 21:382

12. Mahmood F, Bortman J, Amir R et al (2019) Training surgical residents for ultrasound-guided assessment and management of unstable patients. J Surg Educ 76:540-547

13. Kotagal M, Quiroga E, Ruffatto BJ et al (2015) Impact of point-ofcare ultrasound training on surgical residents' confidence. J Surg Educ 72:e82-87

14. Martin JA, Regehr G, Reznick R et al (1997) Objective structured assessment of technical skill (OSATS) for surgical residents. Br J Surg 84:273-278

15. Crouch AK, Dawson M, Long D, Allred D, Madsen T (2010) Perceived confidence in the FAST exam before and after an educational intervention in a developing country. Int J Emerg Med 3:49-52

16. Pulijala Y, Ma M, Pears M, Peebles D, Ayoub A (2018) Effectiveness of immersive virtual reality in surgical training - a randomized control trial. J Oral Maxillofac Surg 76:1065-1072

17. Fonseca AL, Reddy V, Yoo PS, Gusberg RJ, Longo WE (2016) Senior surgical resident confidence in performing flexible endoscopy: what can we do differently? J Surg Educ 73:311-316

18. Happel CS, Lease MA, Nishisaki A, Braga MS (2015) Evaluating simulation education via electronic surveys immediately following live critical events: a pilot study. Hosp Pediatr 5:96-100

19. Schroll R, Smith A, Martin MS et al (2020) Stop the bleed training: rescuer skills, knowledge, and attitudes of hemorrhage control techniques. J Surg Res 245:636-642

20. Tolsgaard MG, Todsen T, Sorensen JL et al (2013) International multispecialty consensus on how to evaluate ultrasound competence: a Delphi consensus survey. PloS one. 8:e57687

21. Alrajab S, Youssef AM, Akkus NI, Caldito G (2013) Pleural ultrasonography versus chest radiography for the diagnosis of pneumothorax: review of the literature and meta-analysis. Crit Care $17: 1-8$

22. Williams R, Windsor A, Rosin RD, Mann DV, Crofton M (1994) Ultrasound scanning of the acute abdomen by surgeons in training. Ann R Coll Surg Engl 76:228

23. Nassour I, Spalding MC, Hynan LS, Gardner AK, Williams BH (2017) The surgeon-performed ultrasound: a curriculum to improve residents' basic ultrasound knowledge. J Surg Res 213:51-59

24. Trajkovski T, Veillette C, Backstein D, Wadey VM, Kraemer B (2012) Resident self-assessment of operative experience in primary total knee and total hip arthroplasty: is it accurate? Can J Surg 55:S153

25. Arora S, Miskovic D, Hull L et al (2011) Self vs expert assessment of technical and non-technical skills inhigh fidelity simulation. Am J Surg 202:500-506

Publisher's Note Springer Nature remains neutral with regard to jurisdictional claims in published maps and institutional affiliations. 